\title{
Persistent Hyperinsulinemic Hypoglycemia in Infancy-A Case Report
}

\section{Nishanth Rajan ${ }^{1}$, Jamuna Kalpana1, Sundaramoorthy Gopi², Viswanathan Mohan ${ }^{2,3}$, Venkatesan Radha ${ }^{2}$ and Lalitha Krishnan ${ }^{1}$}

${ }^{1}$ Department of Paediatrics, Pondicherry Institute of Medical Sciences, Puducherry, India

${ }^{2}$ Department of Molecular Genetics, Madras Diabetes Research Foundation, Chennai, India

${ }^{3}$ Dr. Mohan's Diabetes Specialities Centre, Chennai, India

\author{
Correspondence: \\ Nishanth Rajan \\ Department of Paediatrics, \\ Pondicherry Institute of Medical Sciences, \\ Puducherry, India \\ Email: nishanthwolverine@gmail.com
}

DOI: $10.3126 /$ jnps.v41i1.30806

Submitted on: $2020-07-24$

Accepted on: 2021-02-13

\section{Acknowledgements: None}

Funding: Financial support of Indian Council of Medical Research (ICMR) India, through the project "Investigations of Association of Mutations in MODY and NDM by Translational Genomic Research" awarded to VR for genetic screening, is acknowledged.

Conflict of Interest: None declared Permission from IRB: Yes

To cite this article: Rajan N, Kalpana J, Gopi S, Mohan V, Radha V, Krishnan L. Persistent Hyperinsulinemic Hypoglycemia in Infancy-A case report. J Nepal Paediatr Soc. $2021 ; 41(1): 107-10$.

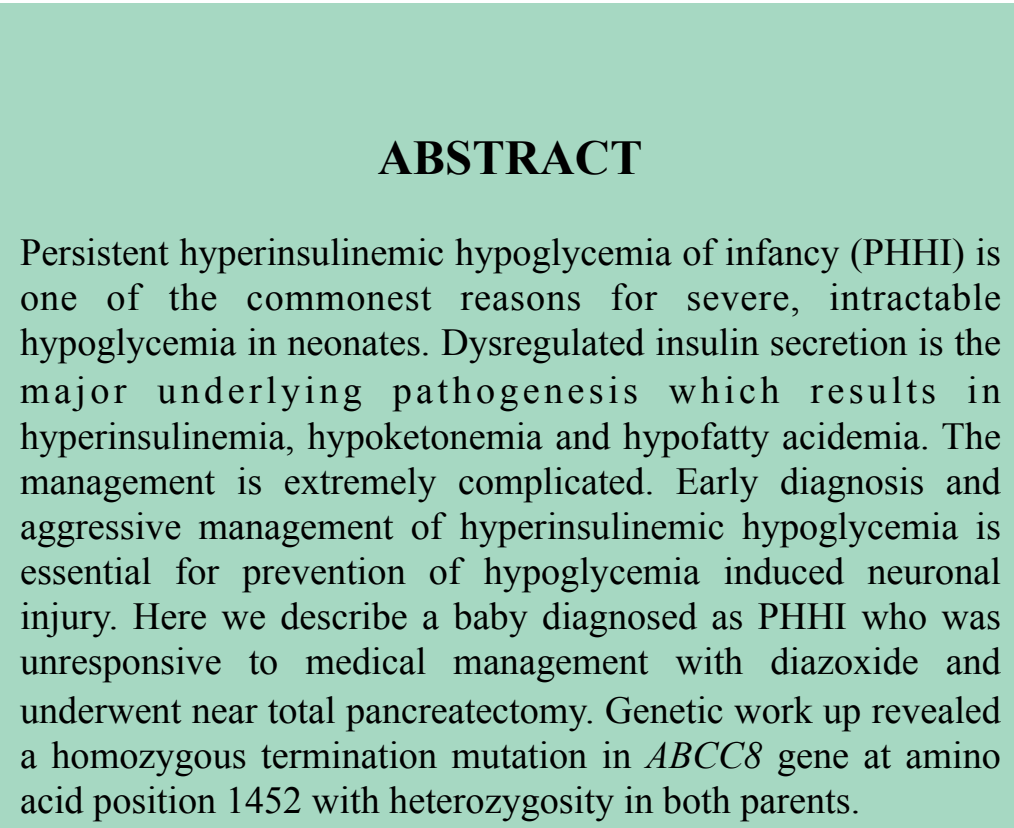

Keywords: $A B C C 8$ mutation; diazoxide; Hypoglycemia; hyperinsulinemia

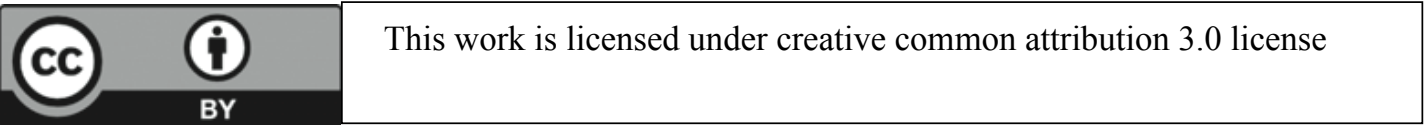




\section{INTRODUCTION}

Persistent hyperinsulinemic hypoglycemia of infancy (PHHI) is rare but one of the commonest reasons for severe, intractable hypoglycemia in neonates. Underlying pathology is dysregulated insulin secretion resulting in hypoglycemia and suppression of lipolysis. ${ }^{1}$ Consequently there is adverse neurodevelopmental outcome, if hypoglycemia is not treated promptly. ${ }^{2}$ PHHI results from mutations in $12 \mathrm{key}$ genes involved in the regulation of insulin secretion from pancreatic $\beta$-cells. ${ }^{3}$ With the advent of L-DOPA PET/CT preoperative differentiation of focal and diffuse lesions has resulted in radical change in therapy for this condition. ${ }^{4}$ We describe a case of PHHI who had presented to us with HIE.

\section{CASE REPORT}

A $3.62 \mathrm{~kg}$ female term baby, was born by cesarean section to first degree consanguineous parents. Mother had an uneventful pregnancy with no gestational diabetes or hypertension. The baby was referred to us as a case of hypoxic-ischemic encephalopathy. At 20 hours of life, baby developed seizures and became cyanosed. On admission, she was profoundly hypoglycemic with undetectable blood sugar levels. She was immediately commenced on glucose infusion at 8 $\mathrm{mg} / \mathrm{kg} / \mathrm{min}$ and increased sequentially to 12 $\mathrm{mg} / \mathrm{kg} / \mathrm{min}$ and then to $20 \mathrm{mg} / \mathrm{kg} / \mathrm{min}$. The critical sample taken at admission revealed hyperinsulinemia (Insulin level $25 \mu \mathrm{IU} / \mathrm{ml}$ ). Urine ketone was negative. The blood sugar values dropped further and hence the baby was given two doses of hydrocortisone and diazoxide was added at $15 \mathrm{mg} / \mathrm{kg} /$ day. Once euglycemia was achieved dextrose was reduced gradually to $10 \mathrm{mg} / \mathrm{kg} / \mathrm{min}$. But on seventh day, there was again an episode of hypoglycemia and diazoxide was increased to 20 $\mathrm{mg} / \mathrm{kg} /$ day. Octreotide was also started and by $12^{\text {th }}$ day of life, blood sugar levels were under control. Tandem mass spectrometry was normal. In view of refractory hypoglycemia, L-DOPA PET scan was done $^{5}$ which showed a diffuse increased $68 \mathrm{Ga}$ DOTANOC radiotracer uptake in body and tail of the pancreatic parenchyma suspicious for diffuse variant of PHHI (Figure 1). A near total pancreatectomy was done at the Institute of Child Health, Chennai. The baby has severe neurological morbidity with microcephaly and developmental delay at eight months of age. Genetic work up revealed a homozygous termination mutation in $A B C C 8$ gene at amino acid position 1452 changing Tryptophan to termination mutation (p.Trp1452Ter ;c.4356 G > A). Both parents, who are first cousins, have been found to be heterozygous for the same condition. In this case parents have been counselled for identifying mutation in the next foetus.

\section{DISCUSSION}

PHHI (Congenital hyperinsulinism) is one of the rare causes for persistent and refractory hypoglycemia. There is hyperinsulinemia, hypoketonemia and hypofatty acidemia. Snider et al. detected mutations in $79 \%$ of their cases (378 of 417). ${ }^{5}$ The incidence can vary between 1 in 40,000
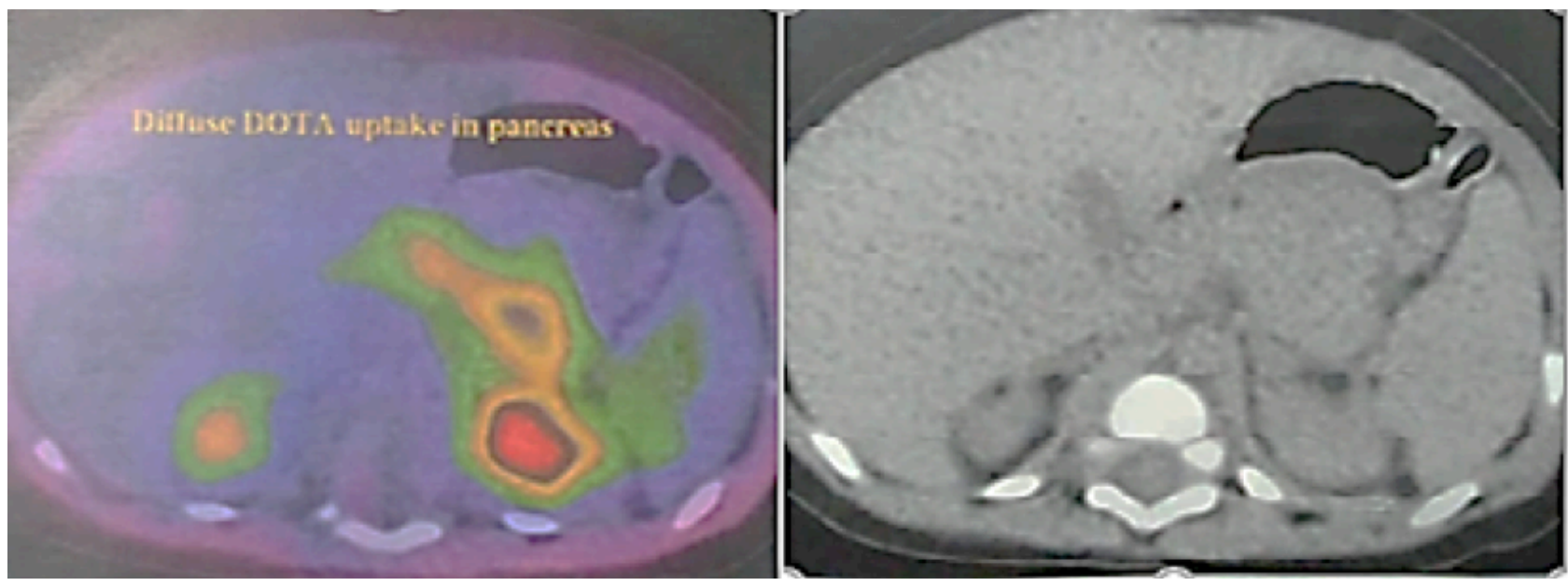

Figure 1: L-DOPA PET scan showing a diffuse increased radiotracer uptake in body and tail of the pancreatic parenchyma 
50,000 in the general population to 1 in 2500 in certain communities with high rates of consanguinity. ${ }^{6}$ Usually neonates present with symptoms and signs of severe hypoglycemia, in our case blood sugar levels at admission were undetectable. The department protocol of sending serum insulin levels before treatment, in all cases of hypoglycemia requiring intravenous glucose, helped us to identify the hyperinsulinemia very early as substantiated by others. ${ }^{7}$ Diagnostic criteria for PHHI includes non ketotic hypoglycemia (Blood sugar levels less than $36 \mathrm{mg} / \mathrm{dL}$ ), both fasting and postprandial, hyperinsulinemia (plasma insulin level $>3 \mathrm{mU} / \mathrm{L}$ ) and need for $20 \mathrm{mg} / \mathrm{kg} /$ minute of glucose infusion rate to maintain blood sugar levels of $>54 \mathrm{mg} / \mathrm{dl}$.

The most severe form of hyperinsulinemia results from recessive inactivating mutations in $A B C C 8$ and $K C N J 11$ genes which encode the two subunits of the adenosine triphosphate sensitive potassium channels (ATP-sensitive $\mathrm{K}+$ channel) in the pancreatic B-cells. ${ }^{8}$

The management is extremely complicated. The mainstay of initial treatment is giving feeds or parenteral glucose to maintain normal sugars. Symptomatic episodes should be treated with dextrose boluses followed by keeping glucose infusion rate high. Diazoxide, octreotide, nifedipine, somatostatin analogues have all been tried by various workers. ${ }^{7,9}$

Surgery has a role in managing this illness when medical therapy fails to achieve euglycemia. With the onset of L-DOPA PET scans, differentiation of diffuse and focal lesions has become easier. The Children's Hospital of Philadelphia reported experience of more than 250 cases of hyperinsulinism of infancy over 10 years. ${ }^{10}$ Focal lesions in the head of the pancreas was found in more than $50 \%$ of cases. Most cases had over 50\% resection of pancreas in their series. More than $90 \%$ of the focal hyperinsulinism cases were cured after surgery. However, in cases of diffuse hyperinsulinism, approximately $50 \%$ of the cases continued to have hypoglycemia after surgery, $25 \%$ of the cases remained well and another one-fourth of the cases managed surgically showed signs of insulin deficiency and required insulin replacement therapy.

\section{CONCLUSIONS}

Early diagnosis and aggressive management of hyperinsulinemic hypoglycemia is essential for prevention of hypoglycemia induced neuronal injury. Diazoxide unresponsiveness in such a baby should prompt a 18F-DOPA-PET scan to classify as focal or diffuse pathology. Molecular diagnosis to look for common mutations is important for genetic counselling as diffuse PHHI is autosomal recessive.

\section{REFERENCES}

1. James C, Kapoor RR, Ismail D, Hussain K. The genetic basis of congenital hyperinsulinism. J Med Genet. 2009 May;46(5):289-99. DOI: 10.1136/jmg.2008.064337

2. Ludwig A, Enke S, Heindorf J, Empting S, Meissner T, Mohnike K. Formal Neurocognitive Testing in 60 Patients with Congenital Hyperinsulinism. Horm Res Paediatr. 2018;89(1):1-6.DOI: 10.1159/000481774

3. Demirbilek H, Hussain K. Congenital Hyperinsulinism: Diagnosis and Treatment Update. J Clin Res Pediatr Endocrinol. 2017 Dec;9(2):69-87. DOI: 10.4274/jcrpe.2017.S007

4. Ismail D, Hussain K. Role of 18F-DOPA PET/CT imaging in congenital hyperinsulinism. Rev Endocr Metab Disord. 2010 Sep;11(3):165-9. DOI: 10.1007/s11154-010-9145-1. 
5. Snider KE, Becker S, Boyajian L, Shyng S-L, MacMullen C, Hughes N, et al. Genotype and phenotype correlations in 417 children with congenital hyperinsulinism. J Clin Endocrinol Metab. 2013 Feb;98(2):E355-363. DOI: $10.1210 /$ jc. $2012-216$

6. Arnoux J-B, Verkarre V, Saint-Martin C, Montravers F, Brassier A, Valayannopoulos V, et al. Congenital hyperinsulinism: current trends in diagnosis and therapy. Orphanet J Rare Dis. 2011 Oct 3;6:63. DOI: 10.1186/1750-1172-6-63

7. Vora S, Chandran S, Rajadurai VS, Hussain K. Hyperinsulinemic Hypoglycemia in Infancy: Current Concepts in Diagnosis and Management. Indian Pediatr. 2015 Dec;52(12):1051-9. DOI: 10.1007/s13312-015-0772-1.

8. Tornovsky S, Crane A, Cosgrove KE, Hussain K, Lavie J, Heyman M, et al. Hyperinsulinism of infancy: novel ABCC8 and KCNJ11 mutations and evidence for additional locus heterogeneity. J Clin Endocrinol Metab. 2004 Dec;89(12):6224-34. DOI: 10.1210/jc.2004-1233.

9. Roženková K, Güemes M, Shah P, Hussain K. The Diagnosis and Management of Hyperinsulinaemic Hypoglycaemia. J Clin Res Pediatr Endocrinol. 2015 Jun;7(2):86-97. DOI: 10.4274/jcrpe.1891

10. Palladino AA, Stanley CA. A specialized team approach to diagnosis and medical versus surgical treatment of infants with congenital hyperinsulinism. Semin Pediatr Surg. 2011 Feb;20(1):32-7. DOI: 10.1053/j.sempedsurg. 2010.10 .008 . 